\title{
Price Discovery in the Stock and Corporate Bond Markets ${ }^{\dagger}$
}

\author{
Yifei Mao *
}

October 31, 2012

\begin{abstract}
This paper uses intraday U.S. bond transaction and stock quote data to investigate whether corporate bonds lead stocks in price discovery of underlying firm value. I use Hasbrouck's (1995) "information share" approach to determine the relative contribution of corporate bond to price discovery. Based on a sample of 214 firms, I find that corporate bond markets contribute $12.6 \%$ on average to price discovery from 2009 to 2011. Corporate bond market price discovery increases with the riskiness of the underlying firm value, and is related to contemporaneous market conditions. The findings are consistent with the informed trading theory and Merton (1973) model.
\end{abstract}

Keywords: Price Discovery, Information Share, Corporate Bond

\footnotetext{
${ }^{\dagger}$ I appreciate helpful advice from and discussions with Craig Holden, Matthew Billett and Jun Yang. I would also like to thank Joel Hasbrouck, for generously sharing price discovery analysis in SAS on his website. I also benefit a lot from the suggestions from Utpal Bhattacharya, Azi Ben-Rephael, Jess Cornaggia, Kimberly Cornaggia, Andrew Ellul, Nandini Gupta, Ryan Israelsen, Robert Jennings, Veronika Pool, Noah Stoffman, Xuan Tian, Charles Trczinka, Zhengyu Wang, Xiaoyun Yu and all other Brown Bag seminar participants in Indiana University. In addition, I am grateful to Yuhang Xing for sharing her coding with me, and Kevin Crotty and Stacey Jacobsen for sharing data cleaning tips with me. All remaining errors are of my own responsibility. All comments can be sent to yifmao@indiana.edu.

${ }^{*}$ Department of Finance, Kelley School of Business, Indiana University.
} 


\section{Introduction}

Most corporate bonds are traded on the over-the-counter (OTC) market, where opacity and complexity offer an attractive enviroment for sophisticated investors. In addition, without disclosure requirement ${ }^{1}$, "bond traders could exploit inside information without worrying that they would be caught" ${ }^{2}$. However, the fixed cash flow associated with corporate bond (in case of no default) might deter informed traders from trading in the corporate bond market. Given these conflicting trading attributes, it is not clear where informed traders are likely to initiate transactions. Hence, it is of interest for us to detect whether there is price discovery and the level of it (if there is) in the corporate bond market.

The price discovery literature is vast, while a large portion of this research is naturally focused on equity markets, the proliferation of alternative securities suggests a myriad of mechanisms through which price discovery may be delivered. For example, the tremendous growth of the contingent claim market during the 1970s suggests that options may be critical to price discovery. However, findings show surprisingly little price discovery in the option market. Chakravarty, Gulen and Mayhew (2004) find the option market's contribution to price discovery to be only 17\%, and Muravyev, Pearson and Broussard (2012) argue that the price discovery in the option market is not economically significant. Given the findings of relatively low price discovery in option and high price discovery in stock, it is even more interesting to investigate corporate bond as a new channel which might dilute price discovery in the stock market.

The improved transparency of the corporate bond market facilitates my study. On July 1, 2002, the National Association of Securities Dealers' (NASD's) implemented the Trade Reporting and Compliance Engine (TRACE) in response to the growing demand for more

\footnotetext{
${ }^{1}$ There is disclosure requirement under insider trading laws for stock, option and equity-linked bond transactions by insiders. However, there is no disclosure requirement for insider-trading activity in regular corporate bonds.

${ }^{2}$ Michael Lewis, 2010, "The Big Short", Page 62.
} 
transparent corporate bond market. The NASD members were required to report over-thecounter bond transactions through the TRACE system over different phases of the TRACE development. On February 7, 2005, Financial Industry Regulatory Authority (FINRA)'s requirement on reporting approximately $99 \%$ of all corporate bond public transactions became effective. Furthermore, on November 3, 2008, liquidity-demander buy-sell side information is disseminated. This buy-sell indicator dissemination is important for my study on corporate bond. Since without intraday bond quotes information, I need to estimated effective spreads of bond transactions with econometric models, and buy-sell indicator improves the estimation precision.

With the greater accessibility of corporate bond data, there has been a growing literature which looks at the relative informational efficiency of corporate bonds to stocks. However, the methodology employed has mostly focused on the lead-lag relationship between stock and bond returns, and the results have been inconclusive. There is no conclusive evidence that bonds lead stocks; Kwan (1996) argue that stock lead bond, while Hotchkiss and Ronen (2002) argue that stocks do not lead bonds.

A possible reason for the different conclusions is rooted in the short coming of the leadlag method. The lead-lag relationship in returns is a general measure, which captures the relation between both the permanent and temporary changes of the prices. To determine price discovery, which is only related to the permanent changes of prices, a Granger leadlag regression is not enough. Furthermore, as Hasbrouck (1995) has pointed out, from an econometric viewpoint, the lead-lag relationship models are misspecified in that convergent representations are assumed in situations where it can be proven that no such representations exist. Under his information share approach, only a minimal structure is imposed on the dynamics of the prices in multiple markets, which achieves most of the functional generality of the lead-lag regression approach. As Hasbrouck (1995) shows in the paper, the information share measure is based on the common permanent component of all the market prices, and the 
component of a market's innovation that helps forecast only transient price disturbances is ignored. In the context of stock and corporate bond, the prices of which are not cointegrated, Hasbrouck (1995)'s information share method could still be applied after first converting stock midpoint quotes to implied bond midpoint quotes by Merton's (1973) model. However, I face some empirical challenges in the special context of corporate bond trading.

First, there is no intraday bond quote information. In an OTC market, there is no centeralized trading place for market makers to update their quotes. Investors get informed about bond quotes by calling around and asking. The lack of quotes brings up two problems. The first one is the presence of microstructure noise such as bid-ask bounce in the transaction prices. I approach this problem by estimating effective spreads with buy-sell indicator and transaction prices using Huang and Stoll (1997) model. Then I adjust the transaction prices to midpoint quotes using effective spread estimates.

The second problem is a large discrepancy in the frequency of bond transactions data with stock quotes data. I approach this problem by matching the closest prior stock quotes to each bond transaction. One concern is that missed stock quotes might contain information and hence the findings of price discovery level in the corporate bond market would be biased upwards. However, this concern implicitly assumes that every bond trading is informative, which is not the case in reality. There are bond transactions due to liquidity, hedging and reasons other than information, and it is unlikely that my study only matches more informed bond trading with uninformed stock trading.

Finally, Merton's model assumes a simple capital structure of one bond for each firm, while most of firms issue more than one bond. I approach this problem in three ways. First, I group multiple bond issues as one bond for each firm. That is, I pool the transactions of each bond issued by one firm together and sort their transactions by trading time. All these transactions are viewed as transactions of one bond. If the bonds issued by the firm are homogeneous in terms of the amount of informed trading, then the method applies well. 
However, if the price discovery process in each bond is very different, then the method is confusing. So I run robustness checks in two ways. In one way, I select the bond which is most likely to have the fastest price discovery for each firm. However, this method is likely to miss price discovery in the bond market and hence bias the results. As another alternative, I pick firms with simple bond structures, that is, firms that issue no more than three bonds.

My findings can be summarized as follows. I find that corporate bonds contribute approximately $12.6 \%$ to price discovery. Then I find that the proportion of corporate bond price discovery varies over time. For example, in my sample period, the proportion of price discovery in bonds peaks in 2009, coinciding with the financial crisis. Cross-sectionally, corporate bond in the low credit rating firms contribute more to price discovery. Moreover, the contribution to price discovery is related to the trading volume and effective spreads of the bond and stock, and the firm volatility.

This paper is the first one which studies the relative informational efficiency of the stock and the bond market using an informational share approach. Different from the lead-lag return relationship approach, the study specifically captures the informed trading in the two markets in this way. In addition, this paper introduces a new way of applying the Merton model with high-frequency data. It is both of practical use and future academic interest. Finally, with the development in TRACE dataset, especially the dissemination of buy-sell information after December 3, 2008, I am able to adjust the transaction prices for the bid-ask bounce using trade indicator models. Due to the data limit, the previous literature did not consider this market microstructure bias using TRACE data in their studies of the stock and the bond market efficiency.

The remainder of the paper is organized as follows. Section 2 discusses the related literature. Section 3 explores the underlying theory and hypotheses development. Section 4 shows empirical methodologies used. Section 5 describes data selection and sample construction. Section 6 exhibits empirical results. Section 7 checks the robustness of results. Section 8 
concludes.

\section{$2 \quad$ Related Literature}

Despite many theoretical studies on the informed trading in the stock and option markets (for example, Back (1993)), the ones directly analyzing informed trading in the stock and corporate bond market are sparse. One argument is that too many informed traders in the equity market could drive the transaction cost too high to a point that they switch to trade in the corporate debt market (Chang and Yu (2010)).

General studies on informed trading of correlated assets in (noisy) rational expectations equilibrium settings also provide insights. Caballe and Krishman (1994) derive the equilibrium in a K-trader, N-asset model of insider trading. They show that the informed traders need to determine the demand for each security independently, since market makers can potentially learn about every security from each order flow. Admati (1985) astudy the noisy rational expectations equilibrium for a class of economies with many risky assets. They find phenomena that do not arise in models with a single risky asset arises in this equilibrium due to the various interactions between assets. Recently, Goldstein, Li and Yang (2012) study a model of informed trading with market segmentation of the correlated assets. They find that adding more informed traders may reduce price informativeness due to different trading motives of different traders.

The current study is also related to the security design literature, where the firms issue securities to induce information. Starting from Boot and Thakor (1993), the basic argument is that firms' revenue-maximizing strategy is to split the claims on the cash flow from the asset into an information-sensitive security (equity) that promotes informed trading and a second claim that is less information-sensitive (corporate bond). Furthermore, Habib and Johnsen (2000) establish a theoretical model which views the placement of debt and outside 
equity as a way to elicit information from equity valuation specialists and debt valuation specialists, respectively. In addition, Fulghieri and Lukin (2001) find that a firm's preference for equity rather than debt depends on the costs of information production, the precision of the information-production technology and the extent of the information asymmetry.

Apart from the theoretical results, the empirical evidence related to price discovery in the corporate bond market usually suffers from lack of high-frequency bond trading data and imprecise method using a granger regression framework.

Using data from Bloomberg and the Center for Research in Stock Prices (CRSP), Kwan (1996) examines the correlation between weekly stock returns and weekly yield changes of bonds issued by the same firm between January 1986 and December 1990, and finds a strong contemporaneous correlation. He argues that this finding suggests the effect of firm-specific information on both stock and bond returns. Furthermore, stocks lead bonds in reflecting firm-specific information but not vice versa, since the lagged stock returns have explanatory power for current bond yield changes, while current stock returns are unrelated to lagged bond yield changes.

However, Hotchkiss and Ronen (2002) reach a different conclusion using daily and hourly high-yield bond transaction prices between January 3, 1995 and October 1, 1995. Their bond returns are obtained from the fixed income pricing system (FIPS) under the reporting requirements of NASD. They find that stocks do not lead bonds in reflecting firm-specific information, information is quickly incorporated into both bond and stock prices after earnings news announcements, and measures of market quality are no poorer for the bonds than for the underlying stocks.

Furthermore, in light of the improvements in transparency of the corporate bond market (the development of TRACE), Downing, Underwood and Xing (2009) examine the leadlag return relation between hourly and daily returns on individual stocks and bonds from October 1, 2004 to December 31, 2005. They obtain bond data from TRACE, and stock 
returns data from the NYSE Trade and Quote (TAQ) database. Their results suggest that stock returns lead nonconvertible bond returns for riskier firms (junk-rated and, to a lesser extent, BBB-rated) and not vice versa, though there is no evidence of a lead-lag relation between the equity and nonconvertible bond returns for safer firms.

There are also studies which investigate the informational role of the corporate bond market using approaches different from lead-lag relationship. Blanco, Brennan and Marsh (2005) test the theoretical arbitrage relation between Credit Default Swap (CDS) prices and credit spreads for a sample of 33 U.S. and European investment-grade firms from January 2, 2001 to June 20, 2002. They find that the investment bond market contributes on average $80 \%$ of price discovery for 27 firms where the equilibrium arbitrage condition holds. They use daily ask and bid prices of CDS and match them with bond yields. Given that CDS trading is expected to be attract a fair amount of informed traders, the existence of price discovery in the investment bond market relative to CDS is a clear evidence of informed trading in the corporate bond market.

Overall, this paper provides direct evidence of price discovery in the corporate bond market, and it contributes to literature at two levels. First, it contributes to literature on price discovery in fragmented markets, using corporate bond as a new testing ground. Given the size of and trading frequency in the corporate bond market $^{3}$, bond is an important channel for information revelation. It is also fundamentally different from options on stock, which use stock as an underlying asset.

Second, it reconciles the conflicts in the findings in the lead-lag literature on stock and bond returns, by documenting the exact amount of time that bond leads stock.

\footnotetext{
${ }^{3}$ Corporate bond market has a market value of 7.9 trillion dollars and 11.1 billion dollars trading per day in the end of 2011, while the equity market has a market value of 15.6 trillion dollars and 7.8 billion dollars trading per day then.According to Securities Industry and Financial Markets Association (SIFMA)http://data.worldbank.org/indicator/CM.MKT.LCAP.CD
} 


\section{Theoretical Framework and Hypotheses Development}

Price discovery in different markets is a reflection of trading choices of informed traders. Informed traders would profit more by trading in the asset with a higher information sensitivity, given information production cost about the underlying firm value is the same for the corporate bond and stock. A small elaboration of Merton's model gives the information sensitivity of the corporate debt ${ }^{4}$ and stock under different states of firm asset. Now let me show the derivation in more detail.

Let $V_{t}$ represent the market value of the firm's assets at time t. Assume the equity value is related to the firm's value by a theoretical pricing model $f($.$) :$

$$
E_{t}=f\left(V_{t} ; \sigma\right)
$$

where $\sigma$ represents one or more parameters governing the volatility of the underlying asset. An estimated market value of total assets is calculated by inverting the model with respect to the underlying asset price:

$$
V_{t}=f^{-1}\left(E_{t} ; \sigma\right)
$$

By definition, $V_{t}$ is the sum of the total equity value and the total debt value, so theoretically the corporate debt value $D_{t}$ should be

$$
D_{t}=V_{t}-E_{t}=f^{-1}\left(E_{t} ; \sigma\right)-E_{t}
$$

where $E_{t}$ is the observed market value of the total equity. Now let us derive the pricing

\footnotetext{
${ }^{4}$ In the context of this paper, I use corporate bond to proxy for corporate debt in my empirical analysis.
} 
function $f($.$) . Assume \mathrm{V}$ follow a geometric Brownian motion:

$$
d V=\mu V d t+\sigma_{v} V d W
$$

where $\mu$ is the instantaneous drift on $V, \sigma_{V}$ is the instantaneous volatility and $d W$ is the increment of a standard Wiener process. Moreover, the market value of the firm's total equity at time $T$ can be viewed as a call option on the underlying value of the firm with a strike price equal to the face value of the firm's debt and a time-to-maturity $T$ :

$$
E_{T}=\operatorname{Max}\left(V_{T}-F, 0\right),
$$

where $F$ is the face value of the firm's debt. Thus, the equity value at time $t$ is given by the Black-Scholes formula:

$$
E_{t}=f\left(V_{t} ; \sigma\right)=V_{t} N\left(d_{1}\right)-F e^{-r T} N\left(d_{2}\right),
$$

where $r$ is the instantaneous risk-free rate, $N()$ is the cumulative standard normal distribution function, $d_{1}$ is given by

$$
d_{1}=\frac{\ln \left(V_{t} / F_{t}\right)+\left(r+0.5 \sigma_{v}^{2}\right) T}{\sigma_{v} \sqrt{T}},
$$

and $d_{2}=d_{1}-\sigma_{V} \sqrt{V}$. So the debt value is given by

$$
D_{t}=V_{t}-E_{t}=V_{t}\left(1-N\left(d_{1}\right)\right)+F e^{-r T} N\left(d_{2}\right),
$$


So the sensitivity of equity value to changes in the mean value of the firm's assets is:

$$
\Delta_{E}=\left(\partial E_{t}\right) /\left(\partial V_{t}\right)=N\left(d_{1}\right),
$$

And the sensitivity of debt value to changes in the mean value of the firm's assets is:

$$
\Delta_{D}=\left(\partial D_{t}\right) /\left(\partial V_{t}\right)=1-N\left(d_{1}\right)
$$

As long as $N\left(d_{1}\right)$ is strictly positive and smaller than 1 , both equity and debt would contemporaneously react to new information about the underlying mean value of the firm's assets. In addition, from microstructure theory we know that when informed traders are trading multiple correlated assets, their optimal trading strategy will be to trade in all informationally sensitive markets. So the informed trading theory and Merton's model together predict that there should be informed trading in both corporate bond market and stock market. I would test a null hypothesis which says:

Null Hypothesis 1: Price discovery that happens first in the corporate bond market ${ }^{5}$ is zero.

If the null is rejected, the evidence would support both Merton's theory and informed trading theory.

However, there are also cases when only one of the two securities reacts to new information arrival. For example, when the firm is extremely safe, that is, when the firm value $V_{t}$ is way larger than the face value of debt $\mathrm{F}, d_{1}$ would be so big that $N\left(d_{1}\right)$ is 1 . In this case, only equity is sensitive to mean value changes of the firm asset. In other cases which are not so extreme, the information sensitivity of debt and equity is associated how risky the underlying firm asset is. For example, a lower $V / F$ ratio, which could roughly proxy for how risky the underlying firm asset is, would result in a lower $d_{1}$, hence a lower equity information

\footnotetext{
${ }^{5}$ It is measured as bond information share, which would be introduced in the methodology part.
} 
sensitivity but a higher debt information sensitivity. From microstructure theory, that when informed traders are trading multiple correlated assets, their optimal trading strategy will be to trade a larger quantity when one of the assets is more informationally sensitive, hence I have the second hypothesis:

Hypothesis 2: Price discovery that happens first in the corporate market is higher for firms with lower credit ratings.

\section{Empirical Methodology}

According to Hasbrouck (1995), information share associated with a particular market is "the proportional contribution of that market's innovations to the innovation in the common efficient price". Intuitively, information share proxies for "who moves first" in the price discovery. I estimate the bond information share following three steps. First, I estimate the

effective bid-ask spread and use it to adjust the bond transaction price to the implied bond midpoint price. Second, I compute the implied bond midpoint price from the midopoint stock quotes using Merton's formula. Third, I use the implied bond midpoint price and the actual bond midpoint price estimated from the trade indicator model in part I to calculate information shares as in Hasbrouck (1995).

\subsection{Effective Spreads}

I estimate the effective bid-ask spread for each bond in each year during my sample period following Huang and Stoll (1997) (denoted as HS from now on), who regress price changes on a buy/sell change indicator and lagged buy/sell indicator. In their generalized model, 
they consider the effect of trade size on effective spreads. Their model is

$\Delta p_{t}=\frac{S^{S}}{2} D_{t}^{S}+\left(\lambda^{S}-1\right) \frac{S^{S}}{2} D_{t-1}^{S}+\frac{S^{M}}{2} D_{t}^{M}+\left(\lambda^{M}-1\right) \frac{S^{M}}{2} D_{t-1}^{M}+\frac{S^{L}}{2} D_{t}^{L}+\left(\lambda^{L}-1\right) \frac{S^{L}}{2} D_{t-1}^{L}+e_{t}$

where $S^{S}, S^{M}$ and $S^{L}$ are effective spreads for small, medium and large trades respectively, and $\lambda^{S}$ represents the percentage inventory cost and adverse selection component of the effective spread.

$D_{t}^{i}(i=S, M, L)$ are variables taking the value of trade indicator $Q_{t}$ depending on whether it is a small $(i=S)$, medium $(i=M)$ or large $i=L$ size trade. $Q_{t}=1$ if it is a customer buy, and $Q_{t}=-1$ if it is a customer sell. Specifically, $D_{t}^{L}=Q_{t}$ if it is a large trade, and $D_{t}^{L}=0$ otherwise; $D_{t}^{M}=Q_{t}$ if it is a medium size trade, and $D_{t}^{M}=0$ otherwise; $D_{t}^{S}=Q_{t}$ if it is a small size trade, and $D_{t}^{S}=0$ otherwise. The cutoff points that I use to separate small, medium and large trades are different for investment grade bonds and high yield bonds ${ }^{6}$. For investment grade bonds, the cutoff points are 2.5 million and 5million, while for high yield bonds the cutoff points are 0.5 million and 1 million respectively ${ }^{7}$.

After estimating the effective spreads for different trade sizes of each bond in each year, I use them to adjust the bond transaction prices to midpoint quotes. If it is a sell transaction, I deduct the effective spread from the transaction price; if it is a buy transaction, I add the effective spread to the transaction price. If it is an interdealer transaction, I do not adjust the transaction price.

\footnotetext{
${ }^{6}$ In TRACE, a bond is investment grade if it is Baa3 or better by Moody's investors service or BBB- or better by Standard \& Poor's Corporation. A bond is rated as high yield if it is Ba1 or lower by Moody's Investors Services or BB+ or below by Standard \& Poor's Corporation.

${ }^{7}$ For investment grade bonds, TRACE only reports " +5 MM" for a transaction with a volume larger than 5 million. For high yield bonds, TRACE only reports "+1MM" for a transaction with a volume larger than 5 million
} 


\subsection{Implied Bond Price}

Chakravarty, Gulen and Mayhew (2004) use Black-Scholes formula to convert option prices to implied stock prices, and then make use of the cointegration between the implied stock prices and the observed stock prices to compute information shares. They argue that "the stock and option prices may be linked by arbitrage, but this does not mean that one can find a constant cointegration vector for the time series of stock and option prices." After converting the option price to the implied stock price, they could compare the two time series on the same scale. Under the same consideration, I use Merton (1974)'s formula to estimate the implied bond price from midpoint stock quotes.

First I compute asset $V_{t}$ using Merton's model at each bond transaction, then I back out debt value at each bond transaction as

$$
D_{t}=V_{t}-E_{t}=V_{t}\left(1-N\left(d_{1}\right)\right)+F e^{-r T} N\left(d_{2}\right)
$$

The implied bond price is estimated as the total market value of the debt divided by the debt face value at each bond transaction:

$$
\hat{B}_{t}=\frac{D_{t}}{F}
$$

A frequently used method to obtain the estimates of $\mathrm{V}$ and $\sigma_{V}$ is by solving simultaneous equations. One equation is Merton's model itself, and the other one is obtained by applying Ito's lemma under the assumptions of Merton's formula. This one shows that the volatilities of the total asset and the equity part are related by the leverage ratio:

$$
\sigma_{E}=\frac{V_{t}}{E_{t}} N\left(d_{1}\right) \sigma_{V}
$$

However, as argued by Crosbie and Bohn (2003), "The model linking equity and asset 
volatility by (12) holds only instantaneously. In practice the market leverage moves around far too much for the volatility equation to provide reasonable results." To avoid the problem, I adopt the method used in Crosbie and Bohn (2003), Vassalou and Xing (2004) ${ }^{8}$ and Bharath and Shumway (2008). These methods do not use equation (12), instead, they only use Merton's model (equation (6)) itself for iteration.

The iteration steps are as follows: I start from an initial value $\sigma_{V}=1$ and use this value of $\sigma_{V}$ and Equation (6) to infer $V$ for each transaction in a month. Then I use this time series of $V$ to estimate asset volatility $\sigma_{V}$ in the month, and substitute it back into equation (6) to back out $V$. I keep iterating until the values of $\sigma_{V}$ from two consecutive iterations converges. My tolerance level is $10^{-4}$.

The other inputs to the iteration include the face value of debt $F$, the instantaneous risk-free rate $r$, the time to maturity $T$, the market value of the equity value at time $t, E_{t}$. For $r$, the risk-free rate, I use the 1-year Treasury Constant Maturity Rate at the end of each month obtained from the Board of Governors of the Federal Reserve system. E, the market value of each firm's equity (in millions of dollars), is computed as the closest prior one to each bond transaction. Specifically, I calculate the product of midpoint stock price quotes and the number of shares outstanding (from CRSP) at the same time with each bond transaction. The time to maturity, $T-t$, is the face-value-weighted time to maturity of all outstanding bonds at each transaction. Face value, $F$, is the book value of long-term liabilities taken from the balance sheet.

However, there are several empirical problems associated with this approach in the context of corporate bonds. One assumption of the Merton model is that the firm only issues one zero-coupon bond with a maturity date $T$, but it is not the case most of the time. For firms that issue multiple bonds, I approach the problem in three ways. In the first way and the main analysis, I pool all the transactions of bonds issued together for each firm, and treat

\footnotetext{
${ }^{8}$ I would like to thank Yuhang Xing for sharing their coding for iteration of Merton's model with me.
} 
them as transactions for one bond. In this case, time to maturity is the face-value-weighted time to maturity of all outstanding bonds at each transaction. In the second way, I select a representative bond each firm, and match its transactions with closest stock quotes. In this case, time to maturity is of this individual bond. In the third way, I restrict analysis a subsample of firms with simple bond structures, that is, firms that only issue one or two bonds.

\subsection{Information Share}

As pointed out by Hasbrouck (1995), securities with the same underlying value traded in different markets are linked by arbitrage and short-term equilibrium considerations, and "arbitrage relationships can be used to transform the derivative price into an implicit stock price that may meaningfully be compared with the actual stock price".

With a linear arbitrage relationship between the prices in different markets, we could make use of the cointegration to estimate information shares. However, when it comes to the stock and the bond price of the same issuer, it is not clear whether they are cointegrated. Furthermore, as predicted by Merton's formula, they are more likely to be linked in a nonlinear way. Hence, the bond price series is transformed to an implied stock price series in the last session by the arbitrage relation between them, and then I apply Hasbrouck's information share approach to analyze the transformed series.

As estimated in the last session, $\hat{B}_{t}$ is the implied bond price from the Merton's formula, and assume $B_{t}$ is the estimated bond midpoint quotes (bond transaction price adjusted by effective spreads). For the information share approach to work, $B_{t}-\hat{B}_{t}$ does not diverge over time. In other words, they are cointegrated.

Let price vector $p$ include both the estimated bond midpoint quote and the implied bond 
price

$$
p_{t}=\left(\begin{array}{c}
B_{t} \\
\hat{B}_{t}
\end{array}\right)=\left(\begin{array}{c}
m_{t}+e_{b, t} \\
\hat{m}_{t}+e_{\hat{b}, t}
\end{array}\right)
$$

Where $m_{t}$ is the underlying common efficient price; $e_{b, t}$ and $e_{\hat{b}, t}$ are zero-mean disturbances that are independently and identically distributed and uncorrelated. Assume $m_{t}$ follow a random walk:

$$
m_{t}=m_{t-1}+\omega_{t}
$$

where $\omega_{t}$ is the random error at time $t . E\left(\omega_{t}\right)=0, E\left(\omega_{t}^{2}\right)=\sigma_{\omega}^{2}$, and $E\left(\omega_{t}, \omega_{s}\right)=0$ for $t \neq s$.

By Granger Representation Theorem, the cointegrated series can be formulated as a vector error correction model of order M:

$$
\Delta p_{t}=A_{1} \Delta p_{t-1}+A_{2} \Delta p_{t-2}+\ldots+A_{M} \Delta p_{t-M}+\gamma\left(z_{t-1}-\mu\right)+u_{t}
$$

where $B_{i}(i=1,2, m)$ matrices are autoregressive coefficients, $\gamma\left(z_{t-1}-\mu\right)$ is the error correction term, $z_{t-1}$ is a column vector documenting price difference, $z_{t-1}=\left[\left(p_{1 t}-p_{2 t}\right),\left(p_{1 t}-\right.\right.$ $\left.\left.p_{3 t}\right)\left(p_{1 t}-p_{n, t}\right)\right]^{\prime}, \mu_{z}=E\left(z_{t-1}\right), \gamma$ is an adjustment coefficient and $u_{t}$ is the disturbance. The covariance matrix of the disturbances is

$$
\operatorname{Cov}\left(u_{t}\right)=E u_{t} u_{t}^{\prime}=\Omega,
$$

Alternatively, the price vector can be represented as a vector moving average model:

$$
\Delta p_{t}=u_{t}+A_{1} u_{t-1}+A_{2} u_{t-2}+\ldots
$$


where $A_{i}(i=1,2, m)$ coefficients are the impulse response parameters. The cumulative impulse response function is :

$$
C_{k}=\Sigma_{i=0}^{k} A_{i}
$$

and $C=\lim _{k \rightarrow \infty} C_{k}$. The rows of $C$ dare all identical. Let $c$ be any row of $C$. So the random-walk component of the prices is:

$$
\omega_{t}=c u_{t}
$$

So the innovation variance is:

$$
\sigma_{\omega}^{2}=c \Omega c^{\prime}
$$

The information share of the jth market is defined as

$$
I S_{j}=\frac{c_{j}^{2} \Omega_{j j}}{c \Omega c^{\prime}}
$$

\section{Data and Sample Construction}

\section{$5.1 \quad$ Data}

I obtain bonds' transaction data from the Financial Industry Regulatory Authority's (FINRA) $\mathrm{TRACE}^{9}$. TRACE consolidates transaction data for all eligible over-the-counter corporate bonds. After February 7, 2005, FINRA's requirement on reporting approximately $99 \%$ of all corporate bond public transactions is effective . In addition, liquidity demander buy-sell side

\footnotetext{
${ }^{9}$ For information regarding TRACE, visit its homepage: http://www.finra.org/industry/compliance/markettransparency/trace/.
} 
information is disseminated for trades after November 3, $2008^{10}$. My sample period covers January 1, 2009 to December 31, 2011, given that buy-sell information is crucial for me to estimate effective spreads of the trace bonds in the analysis below. The only trades that are omitted from TRACE are those that occurred on exchanges.

I also use Mergent Fixed Income Securities Database (FISD) to obtain bond issuing date, maturity date, original offering price, original offering amount and convertible bond indicator. But Mergent FISD does not identify completely TRACE eligible bonds ${ }^{11}$, for those bonds that are not identified by Mergent FISD, I do not include them in the analysis.

I also take stocks' trade and quote data from NYSE Trade and Quote (TAQ), obtain total liability from COMPUSTAT and get 1-year Treasury Constant Maturity Rate at the end of each month obtained from the Board of Governors of the Federal Reserve System ${ }^{12}$.

\subsection{Sample Construction}

Table 1 describes the sample selection process. I start with 56,050 bonds and 5,428 firms with transactions reported in TRACE from January 1, 2009 to December 31, 2011. Then I match bond characteristics and ratings information in MFISD with this group of bonds using the bond's eight-digit CUSIP number. The sample reduces to 38,733 bonds and 3,219 firms after I delete bonds without characteristics or ratings information identified by MFISD.

In the second step, I match the bond issuers to the equity issuers identified in TAQ ${ }^{13}$. Since many bond issuers in TRACE are private firms or subsidiaries with out publicly-traded

\footnotetext{
${ }^{10}$ Information is from http://www.finra.org/web/groups/industry/@ip/@reg/@notice/documents/notices/p039093.pdf.

${ }^{11}$ TRACE eligible securities include all U.S. dollar-denominated debt securities that are depository eligible under NASD Rule 11310(d). Mergent FISD securities include publicly-offered U.S. bonds. Since the data collection system is not the same for the two datasets, there are some bonds which are only included in one of them.

${ }^{12}$ Here is the link to the dataset: http://www.federalreserve.gov/releases/h15/update/.

${ }^{13}$ I do not directly match the two groups together. Instead, I use a CRSP linking table called DSENAMES to facilitate the match. That is, I match the bond issuers to DSENAMES using six-digit CUSIP number and date, while I match the equity issuers in TAQ to DSENAMEs using eight-digit CUSIP number and date. Then I use permno number to match bond issuers with equity issuers.In addition, I delete firms with changing TAQ names during the sample period.
} 
equity, this step reduces the sample dramatically to 5,039 bonds and 1,050 firms.

In the third step, I retain domestic bonds and only bonds issued by industrial firms ${ }^{14}$. I also delete convertible bonds, the pricing of which is too complicated for the current study ${ }^{15}$. There are 2,989 bonds and 649 firms left after this step.

From the fourth to seventh step, I filter the bond transactions reported in TRACE following the standard criteron. First, I delete trades if they are reported before the trade report effective date and after bond maturity date. Then I follow the screening steps documented in Dick-Nielsen (2009). First, I apply three reporting error filters to correct for duplicate trade reports, reversal reports, trade cancellations and corrections ${ }^{16}$. Second, I filter out abnormal price sequences ${ }^{17}$. The next step is special about over-the-counter bond trading. Double reports happen when there are agency transactions. In an agency transaction, the dealer does not have enough inventory to sell bonds to the customer in demand, so he buys from another dealer and passes it to the customer. In this situation, TRACE receives three reports from the two dealers and the customer, and disseminates one dealer transaction report and one customer transaction report ${ }^{18}$. Since I wish to detect informed trading, I should the dealer's trade report in this situation. Finally, I apply the trade bunching ${ }^{19}$ approach

\footnotetext{
${ }^{14}$ I delete bonds with country domicile outside USA, yankee bonds, and bonds identified by MFISD as finance, utility, government or miscellaneous bonds.

${ }^{15}$ I do not delete callable, redeemable or putable bonds, since most of the rest bonds are belong to these categories. If I delete all of them, not many bonds are be left for my analysis.

${ }^{16}$ The trade reports are true duplicates if they have the same message sequence number each day. For these duplicates, I only keep one of them. Reversal trades are trade cancellations for a trade report that was originally submitted into TRACE on a previous day. In this case, I delete both the reversal trade and the original trade identified by looking for the same trade-related information in the previous day (TRACE data in WRDS does not include the filing date of the reports, so I could not directly identify the trades that are reversed). In addition, there are trade cancelations and corrections in the same day. For trade cancellations, I delete both the cancellation trade report and the original trade. For trade corrections, I only delete the original trade.

${ }^{17}$ The price is considered as being abnormal if: price is less than 1 or greater than 500; price is more than $20 \%$ away from the previous trading price; price is more than $20 \%$ away from the median price of the day.

${ }^{18}$ In addition to double counting, there might be commission fees in an agency transaction. TRACE incorporates the commission into the disseminated price, but I could not adjust for commission fees in this case since its amount is not reported.

${ }^{19}$ If trades happening at the same time have the same transaction price and trade initiation side, I aggregate the trading quantities of them and view them as one trade.
} 
used by Huang and Stoll (1997), since a customer/dealer might split his orders in order to reduce information revelation. After bond transactions filtering, there are 2984 bonds and 648 firms left.

From the eighth to the ninth step, I filter out firms without enough trading frequency both ex ante and ex post. Ex ante, before estimating implied bond prices, for bonds that have been issued and not matured yet, I require each of them to be traded at least 10 times to be included in the sample ${ }^{20}$.In addition, I pool bond transactions for each firm together, and require a firm to have at least 100 bond transactions each year to be included in the sample ${ }^{21}$. Ex post, after estimating implied bond prices, the value of which is missing for some bond transactions due to missing observations, I apply the frequency filter to the nonmissing observations again. In the end, the sample reduces to 214 firms, 1644 bonds and transactions.

Table 2 shows the cross-sectional distribution of bond features for my sample and TRACE dataset during the sample period. As reported by this table, most of bonds in my sample are senior bonds, and they are distributed across different age, maturity and credit quality categories.

\section{Results}

The basic issue I wish to address is whether there is significant price discovery happening in the corporate bond market. As discussed above, the results from lead-lag literature are inconclusive. The results from Kwan (1996) suggest stock returns lead bond bond returns and not vice versa, while Hotchkiss and Ronen (2002) show that stock returns do not lead bond returns. In addition, the subsample studies from Downing, Underwood and Xing (2009)

\footnotetext{
${ }^{20}$ Effective spreads estimation is done at the bond level each year. Without each observations, the regression coefficients estimates would not be reliable

${ }^{21}$ I estimate information shares annually, so I need to ensure a fair amount of observations each year.
} 
suggest that stock returns lead nonconvertible bond returns for riskier firms, and there is no evidence of lead-lag relation between stock and nonconvertible bond returns for safer firms. I address this question directly by examining the estimated information share for corporate bond markets. The results reported in Section 6.1, indicate that there is significant price discovery occuring in the corporate bond market.

\subsection{Information Share in Stock and Corporate Bond Markets}

My results indicate that significant price discovery does occur in corporate bond markets. Summary statistics of bond information shares are reported in Table 3 . When the innovations in the two markets are correlated, Hasbrouck's (1995) methodology reports upper- and lowerbounds for information shares. The upper- and lower- bounds in Table 3 are estimated at annual frequency for each firm. The midpoints are the averages of the upper- and lowerbounds. Across the 214 stocks in my sample, the average lower bound on the information share attributable to corporate bond markets is $6 \%$, the average upper bound is $19.2 \%$, and the average midpoint is $12.6 \%$. Based on the standard error of the mean of information share estimates as reported in the table, these averages are significantly different from zero at one percent level.

In the subsequent two sections, I examine the time-series and cross-sectional determinants of variation in estimates of information shares.

\subsection{Time-series Variation in Information Share}

Table 4 reports lower bounds, upper bounds and midpoints of bond information shares each year between 2009 and 2011. The information share attributable to corporate bond market appear to peak in 2009, which coincide with financial crisis. This might be related to riskier underlying firm asset during the financial crisis. According to Hypothesis 2, bond 
information share is higher when underlying firm asset is riskier. The findings in Table support Hypothesis 2.

\subsection{Cross-sectional Variation in Information Share}

In this section, I first directly test Hypothesis 2 by investigating bond information shares for firms with different credit ratings. I separate firms to three credit rating groups. The first group include firms that are rated as AA or up. The second group are firms rated between $\mathrm{BBB}$ and $\mathrm{AA}$. Both groups of firms are considered as investment-grade firms. The third group is the high-yield group, which are firms rated below BBB. Table 5 shows corporate bond information shares across different credit ratings. As can be seen from the table, the bond information shares decrease with an improvement in credit quality as proxied by credit ratings. Furthermore, a t test of means of bond information shares from high yield firms and investment-grade firms (BBB-AA, not including the superior group) shows that the difference between the two groups is significant at 1 percent level. The results from z test of the median also indicates a significant difference in price discovery in different credit ratings groups.

In addition, I examine whether the amount of price discovery in corporate bond market is related to observable market condition. Since trading volume is sometimes used as a proxy for disagreement in literature, I expect to see a relation between trading volume and bond information shares in both markets. There may also be relation between bid-ask spread and price discovery. One one hand, a wider bid-ask spread would increase the transaction costs for informed traders, which would deter them from entering the market. On the other hand, a wider bid-ask spread might be the result of market makers' reaction to a higher probability of informed trading. Finally, I test if there is a relation between firm asset volatility and the level of price discovery in corporate bond markets. I obtain firm asset volatility as a side product from the iteration of Merton's (1973) model in section 4.2. Table 6 reports 
coefficient estimates. The results from this table suggest that bond information share is higher when effective spreads in the stock market is higher relative to the bond market, the trading volume in the stock market is higher relative to the bond market, and the firm volatility is higher.

\section{Robustness Checks}

In order to investigate the sensitivity of my results to empirical design choices, I conduct several robustness checks. In my main analysis, I pool the transactions of bonds issued by the same firm together as one bond. This method is problematic when bonds are heterogenous in terms of price discovery. As one robustness check, I pick the most frequently-traded bond of each firm, and match their transactions with corresponding stock quotes. Table 7 reports bond information shares under this methodology. Under this method, the contribution to

price discovery from corporate bond markets is even larger on average, with a mean of $29.3 \%$ during the sample period. The regression results also hold.

As an alternative robustness check, I pick firms which issue no more than three corporate bonds during the sample period. These firms would have more homogenous bonds than other firms by definition. For this subsample, the average contribution to price discovery from corporate markets is $33.3 \%$. However, most of the regression coefficients are not significant, which could be due to the small sample size.

\section{Conclusion}

This article has applied Hasbrouck's (1995) methodology to the joint time series of estimated midpoint bond prices and stock-implied bond prices, to measure the relative contribution to price discovery from the stock market and the corporate bond market. 
Significant evidence of price discovery in the corporate bond market is found. In addition, corporate bond market tends to be more informative on average when the credit ratings of the firms are lower. Evidence also shows that the relative price discovery in the corporate bond market is higher when the trading volume of stocks relative to bonds is higher, the effective spreads of stocks relative to bonds is higher, and the volatility of underlying firm value is higher.

I also investigate whether the price discovery level in the corporate bond market is robust to empirical designs. I pick the most frequently traded bond for each firm and match their transactions with corresponding stocks. The contribution to price discovery from corporate bond markets is even higher than $29.3 \%$ on average under this matching methodology. Furthermore, I pick firms which issue no more than three corporate bonds during the sample period. The average bond information shares for this subsample are $33.3 \%$. 


\section{References}

[ 1 ] Back, K., 1993, Asymmetric Information and Options, Review of Financial Studies, 6, 435-472.

[ 2 ] Bao, J., J. Pan and J. Wang, 2011, The Illiquidity of Corporate Bonds, Journal of Finance 66 , 911-946.

[ 3 ] Bessembinder, H., W. Maxwell and K. Venkataraman, 2006, Market Transparency, Liquidity Externalities and Institutional trading Costs in Corporate Bonds, Journal of Financial Economics $82,251-288$.

[ 4 ] Bharath, S. and R. Shumway, 2007, Forecasting Default with the Merton Distance to Default Model, Review of Financial Studies 21, 1339-1369.

[ 5 ] Blanco, R., S. Brennan, I. Marsh, 2005, An Empirical Analysis of the Dynamic Relation between Investment-Grade Bonds and Credit Default Swaps, Journal of Finance, 60, 2255-2281.

[ 6 ] Bond, P., A. Edmans and I. Goldstein, The Real Effects of Financial Markets, Annual Reviews of Financial Economics, forthcoming.

[ 7 ] Boot, A. and A. Thakor, 1993, Security Design, Journal of Finance 48, 1349-1378.

[ 8 ] Caballe, J., and M. Krishnan, 1994, Imperfect Competition in a Multi-Security Market with Risk Neutrality, 62, 695-704.

[ 9 ] Chakravarty, S., H. Fulen and S. Mayhew, 2004, Informed Trading in Stock and Option Markets, Journal of Finance 59, 1235-1257.

[ 10 ] Chang, C. and X. Yu, 2010, Informational Efficiency and Liquidity Premium as the Determinants of Capital Structure, Journal of Financial and Quantitative Analysis, 401-440.

[ 11 ] Cornaggia, J. and K. Cornaggia, 2012, Estimating the Costs of Issuer-Paid Credit Ratings, Working Paper.

[ 12 ] Crosbic, P. and J. Bohn, 2003, Modeling Default Risk, Moody's.

[ 13 ] Dick-Nielsen, J., 2009, Liquidity Biases in TRACE, Journal of Fixed Income 19, 43-55.

[ 14 ] Downing, C., S. Underwood and Y. Xing, 2009, The Relative Informational Efficiency of Stocks and Bonds: An Intraday Analysis, Journal of Financial and Quantitative Analysis 44, 10811102.

[ 15 ] Edwards, A., L. Harris and M. Piwowar, 2007, Corporate Bond Market Transaction Costs 
and Transparency, Journal of Finance 62, 1421-1450.

[ 16 ] Eom, Y., J. Helwege and J. Huang, 2004, Structural Models of Corporate Bond Pricing: An Empirical Analysis, Review of Financial Studies 17, 499-544.

[ 17 ] Foucault T. and L. Frescard, 2011, Cross-listing, investment sensitivity to stock price and the learning hypothesis. Working Paper, HEC Paris.

[ 18 ] Goldstein, I., Y. Li and L, Yang, 2012, Speculation and Hedging in Segmented Markets, Working Paper.

[ 19 ] Habib M. and D. Johnsen, 2000, The Private Placement of Debt and Outside Equity as an Information Revelation Mechanism, Review of Financial Studies, 1017-1055.

[ 20 ] Hasbrouck, 1995, One Security, Many Markets: Determining the Contributions to Price Discovery, Journal of Finance 50, 1175-1199.

[ 21 ] Hotchkiss, E., and T. Ronen, 2002, The Informational Efficiency of the Corporate Bond Market: An Intraday Analysis, Review of Financial Studies 15, 1325-1354.

[ 22 ] Huang, R. and H. Stoll, 1997, The Components of the Bid-Ask Spreads: A General Approach, Review of Financial Studies 10, 995-1034.

[ 23 ] Jones, E., S. Mason and E. Rosenfeld, 1984, Contingent Claims Analysis of Corporate Capital Structures: An Empirical Analysis, Journal of finance 39, 611-625.

[ 24 ] Kwan, S., 1996, Firm-specific Information and the Correlation between Individual Stocks and Bonds, Journal of Financial Economics 40, 63-80.

[ 25 ] Merton, R., 1974, On the Pricing of Corporate Debt: This Risk Structure of Interest Rates, Journal of Finance 29, 449-470.

[ 26 ] Muravyev, D., N. Pearson and J. Broussard, forthcoming, Is there Price Discovery in Equity Options? Journal of Financial Economics.

[ 27 ] Vassalou, M., and Y. Xing, 2004, Default Risk in Equity Returns, Journal of Finance 59, 831-868. 


\section{Table 1. Sample Construction}

This table reports the number of firms, bonds and trades left after each step of data cleaning. The sample period is January 1, 2009 to December 31,2011. In step 1, bonds without information from MFISD are excluded. In step 2, bonds without publicly-traded equity in TAQ are excluded. In step 3, financial firms, utility firms and convertible bonds are excluded. In step 4, corrections for reporting errors (trades which are executed before trade report effective date and after bond maturity date, duplicate reports, reversal reports, same-day correction and cancelation) are performed. In step 5, the abnormal prices are deleted. Step 6 includes corrections for agency transactions. In step 7, there is trade bunch. Step 8 is performed after screening transactions and before computing implied bond prices. Each firm included in this step is required to have at least 100 bond transactions each year. Step 9 is done after applying effective spread regressions and computing implied bond prices. Again, each firm included in this step is required to have at least 100 bond transactions each year.

\begin{tabular}{lccc}
\hline \hline & Firms & Bonds & Tades \\
\hline Panel A Bond selection & 5428 & 56050 & 32258677 \\
All bonds in TRACE & 3219 & 38733 & 29766723 \\
Step (1) Match with MFISD & 1050 & 5039 & 14575901 \\
Step (2) Match with TAQ & 649 & 2989 & 7856417 \\
Step (3) Exclude special bond types & & & \\
\hline Panel B Bond transaction screening & 649 & 2985 & 7112793 \\
Step (4) Correct for reporting errors & 649 & 2984 & 7109325 \\
Step (5) Correct for abnormal price sequence & 648 & 2984 & 6113286 \\
Step (6) Correct for agency transaction & 648 & 2984 & 5898905 \\
Step (7) Trade bunch & & & \\
\hline Panel C Bond trading frequency screening & 404 & 2444 & 5683258 \\
Step (8) Ex ante & 214 & 1664 & 3722044 \\
Step (9) Ex post
\end{tabular}




\section{Table 2. Cross-Sectional Bond Characteristics}

This table characterizes the cross-sectional distributions of various bond features in my sample and in TRACE dataset. The information about bonds characteristics is from MFISD. The bonds are classified into age categories based on their average age in the sample period. The bond credit ratings are based on average Moody's rating during the sample period.

\begin{tabular}{lcccc}
\hline \hline & \multicolumn{3}{c}{ Bonds in Sample } & \multicolumn{2}{c}{ Bonds in TRACE } \\
& Number & Percent & Number & Percent \\
\hline Total number of Bonds & 1644 & 1 & 38733 & 1 \\
Industry & & & & \\
$\quad$ Industrial & 1644 & 1.0 & 6767 & 17.5 \\
Finance & 0 & 0.0 & 20868 & 53.9 \\
Utility & 0 & 0.0 & 1496 & 3.9 \\
Government & 0 & 0.0 & 9565 & 24.9 \\
Miscelleous & 0 & 0.0 & 37 & 0.1 \\
Level & & & & \\
Senior secured & 22 & 1.2 & 843 & 1.3 \\
Senior & 1606 & 96.1 & 35654 & 97.7 \\
Senior subordinate & 33 & 2.4 & 985 & 2.0 \\
Junior & 0 & 0.0 & 2 & 0.0 \\
Junior subordinate & 3 & 0.1 & 54 & 0.1 \\
Subordinate & 0 & 0.0 & 938 & 2.4 \\
Bond complexity features & & & & \\
Convertible & 0 & 0.0 & 337 & 0.9 \\
Callable & 1411 & 85.8 & 23061 & 59.5 \\
Putable & 19 & 1.2 & 443 & 1.14 \\
Redeemable & 1478 & 89.9 & 24492 & 63.2 \\
Exchangeable & 0 & 0.0 & 196 & 0.5 \\
Sinking fund & 1 & 0.1 & 123 & 0.3 \\
Floating rate coupon & 64 & 3.9 & 2583 & 6.7 \\
With covenant & 1623 & 98.7 & 8613 & 22.2 \\
Combination of floating/fixed & 3 & 0.2 & 1100 & 2.8 \\
Asset Backed & 0.0 & 69 & 0.2 \\
\hline \hline
\end{tabular}




\begin{tabular}{|c|c|c|c|c|}
\hline & \multicolumn{2}{|c|}{ Bonds in Sample } & \multicolumn{2}{|c|}{ Bonds in TRACE } \\
\hline & Number & Percent & Number & Percent \\
\hline \multicolumn{5}{|l|}{ Type of issue } \\
\hline Global & 766 & 46.6 & 3949 & 10.2 \\
\hline Foreign & 0 & 0.0 & 4610 & 11.9 \\
\hline Rule 144a issue & 0 & 0.0 & 124 & 0.3 \\
\hline \multicolumn{5}{|l|}{ Country domicle } \\
\hline USA & 1644 & 100.0 & 33283 & 85.9 \\
\hline Foreign & 0 & 0.0 & 5450 & 14.1 \\
\hline \multicolumn{5}{|l|}{ Age } \\
\hline $0-1$ year & 201 & 12.2 & 9032 & 23.3 \\
\hline $1-3$ year & 433 & 26.3 & 8790 & 22.7 \\
\hline $3-5$ year & 312 & 19.0 & 4241 & 10.9 \\
\hline$>5$ year & 509 & 31.0 & 8595 & 22.2 \\
\hline \multicolumn{5}{|l|}{ Maturity } \\
\hline $0-1$ year & 111 & 6.8 & 3491 & 9.0 \\
\hline $1-3$ year & 257 & 15.6 & 7044 & 18.2 \\
\hline $3-5$ year & 238 & 14.5 & 6153 & 15.9 \\
\hline$>5$ year & 849 & 51.6 & 13970 & 36.1 \\
\hline \multicolumn{5}{|l|}{ Orignial maturity } \\
\hline$\leq 10$ year & 909 & 55.3 & 27269 & 70.4 \\
\hline$>10$ year & 755 & 45.9 & 11417 & 29.5 \\
\hline \multicolumn{5}{|l|}{ Credit Quality } \\
\hline Superior (AA and up) & 173 & 8.2 & 17819 & 46.0 \\
\hline Other investment grade (BBB-A) & 1245 & 75.7 & 13086 & 33.8 \\
\hline High yield (below BBB) & 246 & 15.0 & 7828 & 20.2 \\
\hline \multicolumn{5}{|l|}{ Issue size } \\
\hline Small $(<\$ 100$ million $)$ & 26 & 1.6 & 26553 & 68.6 \\
\hline Medium ( $\$ 100$ to $\$ 500$ million) & 946 & 57.5 & 8353 & 21.6 \\
\hline Large $(>\$ 500$ million $)$ & 692 & 42.1 & 3827 & 9.9 \\
\hline
\end{tabular}


Table 3. Corporate Bond Market Information Shares

This table reports upper bounds, lower bounds and midpoints of corporate bond information shares during the sample period. Stderr refers to standard errors of means.

\begin{tabular}{lccc}
\hline \hline & Upper Bound & Lower Bound & Midpoint \\
\hline $\mathrm{N}$ & 642 & 642 & 642 \\
Mean & 0.192 & 0.060 & 0.126 \\
Stderr & 0.009 & 0.006 & 0.007 \\
Min & 0.000 & 0.000 & 0.000 \\
1st Quartile & 0.035 & 0.003 & 0.023 \\
Median & 0.099 & 0.012 & 0.060 \\
3rd Quartile & 0.243 & 0.034 & 0.144 \\
Max & 1.000 & 1.000 & 1.000 \\
\hline \hline
\end{tabular}


Table 4. Corporate Bond Market Information Shares Over Time This table shows the time variation of the bond information shares. Stderr refers to standard errors of means.

\begin{tabular}{cccc}
\hline \hline & 2009 & 2010 & 2011 \\
\hline $\mathrm{N}$ & 214 & 214 & 214 \\
Upper Bound & & & \\
Mean & 0.297 & 0.132 & 0.147 \\
Median & 0.202 & 0.066 & 0.071 \\
Stderr & 0.019 & 0.012 & 0.014 \\
Lower Bound & & & \\
Mean & 0.092 & 0.039 & 0.048 \\
Median & 0.022 & 0.008 & 0.009 \\
Stderr & 0.014 & 0.008 & 0.011 \\
Midpoint & & & \\
Mean & 0.195 & 0.085 & 0.098 \\
Median & 0.120 & 0.042 & 0.041 \\
Stderr & 0.015 & 0.01 & 0.012 \\
\hline \hline
\end{tabular}


Table 5. Corporate Bond Market Information Shares across Credit Ratings This table reports the distribution of midpoint bond market information shares across different credit ratings. Panel A shows summary statistics for three groups of firms. The superior group of firms is rated AA or up, the other investment-grade firms are rated BBB-AA, and the high yield group is rated below BBB. Panel $\mathrm{B}$ shows the results for $\mathrm{t}$ test of mean information share, and $\mathrm{z}$ test of median information share between the investment group (BBB-AA) and the high yield (below BBB) group of firms. Credit ratings are based on the average Moody's rating during the sample period. $* * *$ indicates significance at $1 \%$ level.

\begin{tabular}{|c|c|c|c|}
\hline & 2009 & 2010 & 2011 \\
\hline \multicolumn{4}{|c|}{ Superior (AA and up) } \\
\hline $\mathrm{N}$ & 12 & 12 & 12 \\
\hline Median & 0.076 & 0.021 & 0.031 \\
\hline Mean & 0.12 & 0.044 & 0.054 \\
\hline Std err & 0.039 & 0.015 & 0.019 \\
\hline \multicolumn{4}{|c|}{ Other Investment grade (BBB-AA) } \\
\hline $\mathrm{N}$ & 137 & 137 & 137 \\
\hline Median & 0.108 & 0.037 & 0.036 \\
\hline Mean & 0.166 & 0.082 & 0.08 \\
\hline Std err & 0.017 & 0.011 & 0.013 \\
\hline \multicolumn{4}{|c|}{ High yield (Below BBB) } \\
\hline $\mathrm{N}$ & 64 & 64 & 64 \\
\hline Median & 0.194 & 0.059 & 0.069 \\
\hline Mean & 0.272 & 0.098 & 0.143 \\
\hline Std err & 0.032 & 0.02 & 0.027 \\
\hline
\end{tabular}

Panel B

\begin{tabular}{ccc}
\hline \hline & Difference in Mean & $\mathrm{T}$ value \\
Ttest & $0.062^{* * *}$ & 3.78 \\
\hline \multirow{3}{*}{ Ztest } & Difference in Median & $\mathrm{Z}$ value \\
\hline \hline
\end{tabular}


Table 6. Determinants of Corporate Bond Market Price Discovery

This table reports coefficient estimates and t-statistics for the following regression model:

$$
I S_{i t}=a_{1}+b_{1} \text { SpreadRatio }_{i t}+b_{2} \text { VolumeRatio }_{i t}+b_{3} \text { AssetVol }_{i t}+b_{4} \text { CreditRating }_{i}
$$

where $I S_{i t}$ is the time-series average midpoint of the lower and upper bound on the corporate bond market information share, SpreadRatio $i t$ is the ratio of effective stock spread to effective bond spread, VolumeRatio $i t$ is the ratio of stock volume to bond volume, AssetVol ${ }_{i t}$ is the annualized volatility of underlying firm asset, and CreditRating is the average credit rating of firm $i$ during the sample period. The numbers in parentheses are $\mathrm{t}$ values. $* * *$ indicates significance at $1 \%$ level.

\begin{tabular}{lcccc}
\hline \hline Intercept & Credit Rating & Volume Ratio & Spread Ratio & Asset Volatility \\
\hline $0.12^{* * *}$ & $-0.01^{* * *}$ & $5.58^{* * *}$ & $3.3^{* * *}$ & $0.07^{* * *}$ \\
$(3.92)$ & $(-3.15)$ & $(6.26)$ & $(3.63)$ & $(11.89)$ \\
\hline
\end{tabular}

Number of obs.:639

Adj. R square: 0.302 


\section{Table 7. Information Shares on Individual Bonds}

This table reports corporate bond information shares when only the most-frequently-traded bond is selected for each firm. Panel A shows the summary statistics for upper bounds, lower bounds and midpoints. Stderr refers to standard errors of means. Panel B reports coefficient estimates and t-statistics for the following regression model:

$$
I S_{i t}=a_{1}+b_{1} \text { SpreadRatio }_{i t}+b_{2} \text { VolumeRatio }_{i t}+b_{3} \text { AssetVol }_{i t}+b_{4} \text { CreditRating }_{i}
$$

where $I S_{i t}$ is the time-series average midpoint of the lower and upper bound on the corporate bond market information share, SpreadRatio $o_{i t}$ is the ratio of effective stock spread to effective bond spread, VolumeRatio it is the ratio of stock volume to bond volume, AssetVol $_{i t}$ is the annualized volatility of underlying firm asset, and CreditRating ${ }_{i}$ is the average credit rating of firm $i$ during the sample period. The numbers in parentheses are $\mathrm{t}$ values. ${ }^{* * *}$ indicates significance at $1 \%$ level.

Panel A

\begin{tabular}{lccc}
\hline \hline & Upper Bound & Lower Bound & Midpoint \\
\hline $\mathrm{n}$ & 477 & 477 & 477 \\
mean & 0.293 & 0.49 & 0.095 \\
stderr & 0.008 & 0.012 & 0.007 \\
min & 0.004 & 0.006 & 0.000 \\
1st Quartile & 0.171 & 0.269 & 0.009 \\
median & 0.275 & 0.476 & 0.034 \\
3rd Quartile & 0.374 & 0.692 & 0.105 \\
max & 0.964 & 0.999 & 0.946 \\
\hline \hline
\end{tabular}

Panel B

\begin{tabular}{lcccc}
\hline \hline Intercept & Credit Rating & Volume Ratio & Spread Ratio & Asset Volatility \\
$0.12^{* * *}$ & $0.01^{* * *}$ & $4.03^{* * *}$ & $4.54^{* * *}$ & $0.03^{* * *}$ \\
$(3.19)$ & $(3.57)$ & $(4.51)$ & $(3.84)$ & $(4.68)$ \\
\hline
\end{tabular}

Number of obs.:477

Adj. R square: 0.1364 


\section{Table 8. Bond Information Shares for Subsample Firms}

This table reports corporate bond information shares for a subsample of firms which issue no more than three corporate bonds in the sample period. Panel A shows the summary statistics for upper bounds, lower bounds and midpoints. Stderr refers to standard errors of means. Panel B reports coefficient estimates and t-statistics for the following regression model:

$$
I S_{i t}=a_{1}+b_{1} \text { SpreadRatio }_{i t}+b_{2} \text { VolumeRatio }_{i t}+b_{3} \text { AssetVol }_{i t}+b_{4} \text { CreditRating }_{i}
$$

where $I S_{i t}$ is the time-series average midpoint of the lower and upper bound on the corporate bond market information share, SpreadRatio $i t$ is the ratio of effective stock spread to effective bond spread, VolumeRatio $i t$ is the ratio of stock volume to bond volume, AssetVol ${ }_{i t}$ is the annualized volatility of underlying firm asset, and CreditRating ${ }_{i}$ is the average credit rating of firm $i$ during the sample period. The numbers in parentheses are $\mathrm{t}$ values. $* * *$ indicates significance at $1 \%$ level.

Panel A

\begin{tabular}{lccc}
\hline \hline & Upper Bound & Lower Bound & Midpoint \\
\hline $\mathrm{n}$ & 165 & 165 & 165 \\
mean & 0.333 & 0.104 & 0.219 \\
stderr & 0.023 & 0.017 & 0.018 \\
min & 0 & 0 & 0 \\
1st Quartile & 0.091 & 0.003 & 0.059 \\
median & 0.233 & 0.021 & 0.14 \\
3rd Quartile & 0.487 & 0.076 & 0.283 \\
max & 1 & 0.993 & 0.995 \\
\hline \hline
\end{tabular}

Panel B

\begin{tabular}{lcccc}
\hline \hline Intercept & Credit Rating & Volume Ratio & Spread Ratio & Asset Volatility \\
0.11 & -0.00 & 3.12 & 3.49 & $0.09^{* * *}$ \\
$(1.55)$ & $(-0.19)$ & $(0.29)$ & $(1.07)$ & $(5.46)$ \\
\hline
\end{tabular}

Number of obs.:165

Adj. R square: 0.1610 